\title{
The Type 3 Adenylyl Cyclase Is Required for Novel Object Learning and Extinction of Contextual Memory: Role of cAMP Signaling in Primary Cilia
}

\author{
Zhenshan Wang, ${ }^{1}$ Trongha Phan, ${ }^{2}$ and Daniel R. Storm ${ }^{2}$ \\ ${ }^{1}$ College of Life Science, Hebei University, Baoding, People's Republic of China 071002, and ²Department of Pharmacology, University of Washington \\ School of Medicine, Seattle, Washington 98195
}

\begin{abstract}
Although primary cilia are found on neurons throughout the brain, their physiological function remains elusive. Human ciliopathies are associated with cognition defects, and transgenic mice lacking proteins expressed in primary cilia exhibit defects in learning and memory. Recently, it was reported that mice lacking the G-protein-coupling receptor somatostatin receptor-3 (SSTR3), a protein expressed predominately in the primary cilia of neurons, have defective memory for novel object recognition and lower cAMP levels in the brain. Since SSTR3 is coupled to regulation of adenylyl cyclase, this suggests that adenylyl cyclase activity in primary cilia of CNS neurons may be critical for some forms of learning and memory. Because the type 3 adenylyl cyclase (AC3) is expressed in primary cilia of hippocampal neurons, we examined $\mathrm{AC} 3^{-I-}$ mice for several forms of learning and memory. Here, we report that $\mathrm{AC}^{-1-}$ mice show no short-term memory for novel objects and fail to exhibit extinction of contextual fear conditioning. They also show impaired learning and memory for temporally dissociative passive avoidance. Since AC3 is exclusively expressed in primary cilia, we conclude that cAMP signals generated within primary cilia contribute to some forms of learning and memory, including extinction of contextual fear conditioning.
\end{abstract}

\section{Introduction}

Primary cilia are antenna-like organelles found on many animal cells that project from the apical surface of the cell into the extracellular space (for review, see Singla and Reiter, 2006). In mammals, almost every cell possesses a single primary cilium (Snell et al., 2004; Praetorius and Spring, 2005). A variety of receptors, ion channels, and transporter proteins, as well as their downstream effectors, are found in cilia or their basal bodies, suggesting that primary cilia are specialized structures for signal transduction (Satir et al., 2010). For example, components of the cAMP signal transduction pathway, including G-protein-coupled receptors, adenylyl cyclases (AC3, AC4, AC6, and AC8), and protein kinase A (RI- $\beta$ and RII- $\alpha$ ), have been found in primary cilia of bile cholangiocytes (Masyuk et al., 2008), bone cells (Kwon et al., 2010), and renal epithelial cells (Raychowdhury et al., 2009), implying that primary cilia may serve as a subcellular compartment for cAMP signaling (Johnson and Leroux, 2010).

Cognitive impairment is associated with several ciliopathyrelated syndromes (Lee and Gleeson, 2010), suggesting that primary cilia in CNS neurons are important for cognition. The majority of neurons in the hippocampus, which plays an important role in several forms of memory, have primary cilia (Berbari

Received Dec. 15, 2010; revised Jan. 27, 2011; accepted Feb. 5, 2011.

This research was funded by National Institutes of Health (NIH) Grants NS 020498 and MH 073601 to D.R.S. and Z.W. T.P. was funded in part by NIH Neurobiology Training Grant 5 T32 GM07108. We thank members of the Storm laboratory for critical reading of this manuscript.

Correspondence should be addressed to Dr. Daniel R. Storm, Department of Pharmacology, University of Washington, Seattle, WA 98195. E-mail: dstorm@u.washington.edu.

DOI:10.1523/JNEUROSCI.6561-10.2011

Copyright $\odot 2011$ the authors $\quad 0270-6474 / 11 / 315557-05 \$ 15.00 / 0$ et al., 2007). Moreover, several G-protein-coupled receptors that couple to adenylyl cyclase, including SSTR3 (Händel et al., 1999; Schulz et al., 2000) and melanin-concentrating hormone receptor 1 (MCHR1) (Berbari et al., 2008), are located in primary cilia of hippocampal neurons. Recently, it was discovered that SSTR $3^{-1-}$ mice are severely impaired in memory for novel objects (Einstein et al., 2010). Furthermore, mice without a functional MCHR1 gene also exhibit defective learning and memory (Adamantidis et al., 2005). This supports the hypothesis that primary cilia in neurons play an important role in learning and memory and suggests that regulation of adenylyl cyclase activity in primary cilia of neurons may be critical for some forms of learning and memory.

In the hippocampus and cortex of brain, AC3 is expressed exclusively in the primary cilia of neurons; its concentration in primary cilia is a striking example of subcellular compartmentalization of a signaling protein (Bishop et al., 2007). Given that $\mathrm{SSTR}^{-1-}$ mice have impaired memory for novel object recognition (Einstein et al., 2010) and SSTR3 couples to regulation of adenylyl cyclase, we wondered whether AC3 is required for specific types of learning and memory, including novel object recognition. Here we report that $\mathrm{AC} 3^{-1-}$ mice exhibit deficits in memory for temporally dissociative passive avoidance (TDPA), novel object recognition, and contextual fear extinction. We conclude that AC3 generates a cAMP signal in primary cilia that is required for some forms of learning and memory.

\section{Materials and Methods}

Mice. $\mathrm{AC}^{+/+}$and littermate $\mathrm{AC} 3^{-1-}$ mice were bred from heterozygotes and genotyped as previously reported (Wang et al., 2009b). Basal 
adenylyl cyclase activity in the hippocampus of $\mathrm{AC}^{+1+}$ and $\mathrm{AC}^{-1-}$ mice is $175 \pm 5$ and $155 \pm 8 \mathrm{pmol}$ of $\mathrm{cAMP} \cdot \mathrm{mg}^{-1} \cdot \mathrm{min}^{-1}$, respectively. The age of animals used in this study was 3-8 months old. All of the mice used in this study were males. Mice were maintained on a $12 \mathrm{~h} \mathrm{light/dark} \mathrm{cycle} \mathrm{at} 22^{\circ} \mathrm{C}$, and had access to food and water ad libitum. Mice were housed individually and handled daily for at least 1 week before behavioral experiments to minimize stress. All animal procedures were approved by the Institutional Animal Care and Use Committee at the University of Washington and performed in accordance with their guidelines.

Immunohistochemistry. The immunohistochemistry of hippocampal slices was performed as described previously (Wang et al., 2009b).

TDPA paradigm. This procedure was performed as described previously (Wang et al., 2004a, 2009a; Zhang et al., 2008). On the training day, mice were placed into the light side of a shuttle box consisting of two compartments connected by a door; one side was well lit, and the other side was dark (Coulbourn Instruments). The mice were allowed to explore the environment for $2 \mathrm{~min}$ before the door between the two compartments was opened. The time that each mouse crossed over into the dark compartment was recorded. After the mouse crossed over into the dark compartment (all four paws in the dark compartment), the door was closed, and 10 min later, the mouse received a mild footshock $(0.7 \mathrm{~mA}, 2 \mathrm{~s})$. Twenty-four hours after the first training session, the trained mice were placed into the light compartment again. Their crossover latencies into the dark side were monitored and they received a footshock 10 min after they entered into the dark side. This procedure was repeated several days until their crossover latencies reached a cutoff time of $300 \mathrm{~s}$. The mice were removed if they failed to enter the dark side after $300 \mathrm{~s}$, and a crossover latency of $300 \mathrm{~s}$ was recorded. For analysis of short-term memory, the animals were trained only once, and their crossover latencies were recorded $10 \mathrm{~min}$ later after training.

Contextual fear conditioning. Contextual fear conditioning was performed as we described previously (Wang et al., 2004b). Contextual memory extinction was monitored by returning the mice to the original training box on successive days without shock and monitoring the percentage of time spent freezing during a 2 min period.

Novel object recognition test. The novel object recognition test was performed as described previously (Wang et al., 2004b; Shimizu et al., 2007).

Statistical analysis. All data were presented as means \pm SEM. We analyzed the data by Student's $t$ test for two-sample comparison and oneway ANOVA for multiple-sample comparisons, with $p<0.05$ considered as statistically significant.

\section{Results}

AC3 is highly expressed in the primary cilia of the hippocampus

Although it was reported that AC3 is almost a universal marker for primary cilia throughout the mouse brain (Bishop et al., 2007), it was important to verify the specificity of the antibody
$\mathrm{AC}^{+/+}$
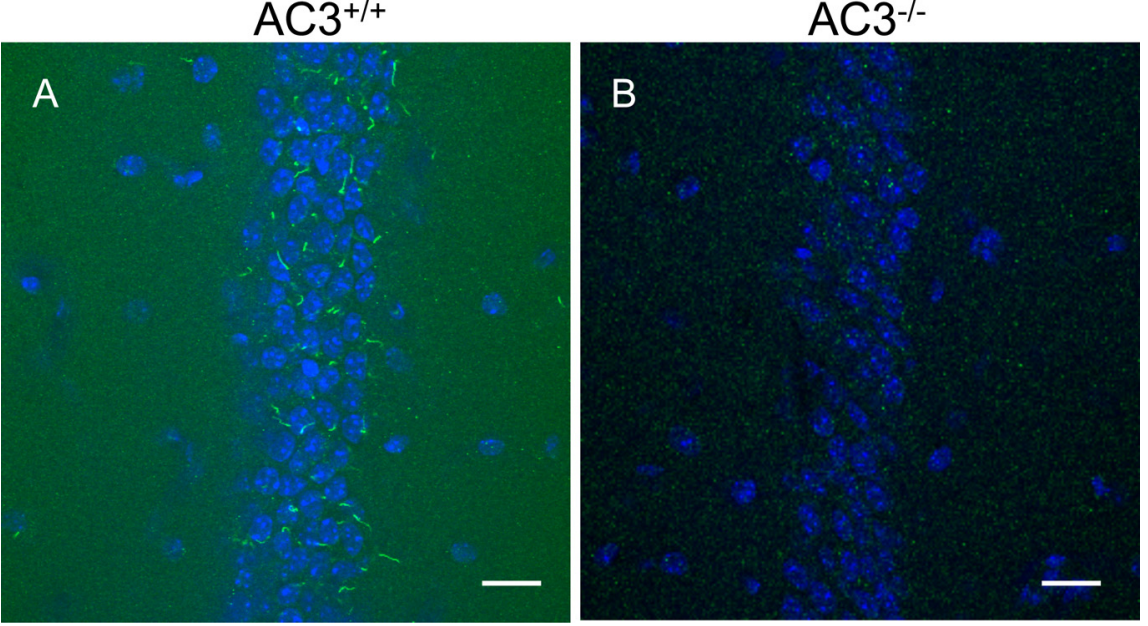

Figure 1. $A C 3$ is highly expressed in the primary cilia of neurons in the $C A 1$ region of the hippocampus. $A, B$, Representative images of staining for $\mathrm{AC} 3$ in primary cilia of neurons in the $\mathrm{CA} 1$ region of the hippocampus for $\mathrm{AC} 3^{+/+}$mice $(A)$ and $\mathrm{AC} 3^{-1-}$ mice B). Scale bar, $20 \mu \mathrm{m} . n=4$ for each genotype. Green, $\mathrm{AC} 3$; blue, Hoechst nuclear staining.
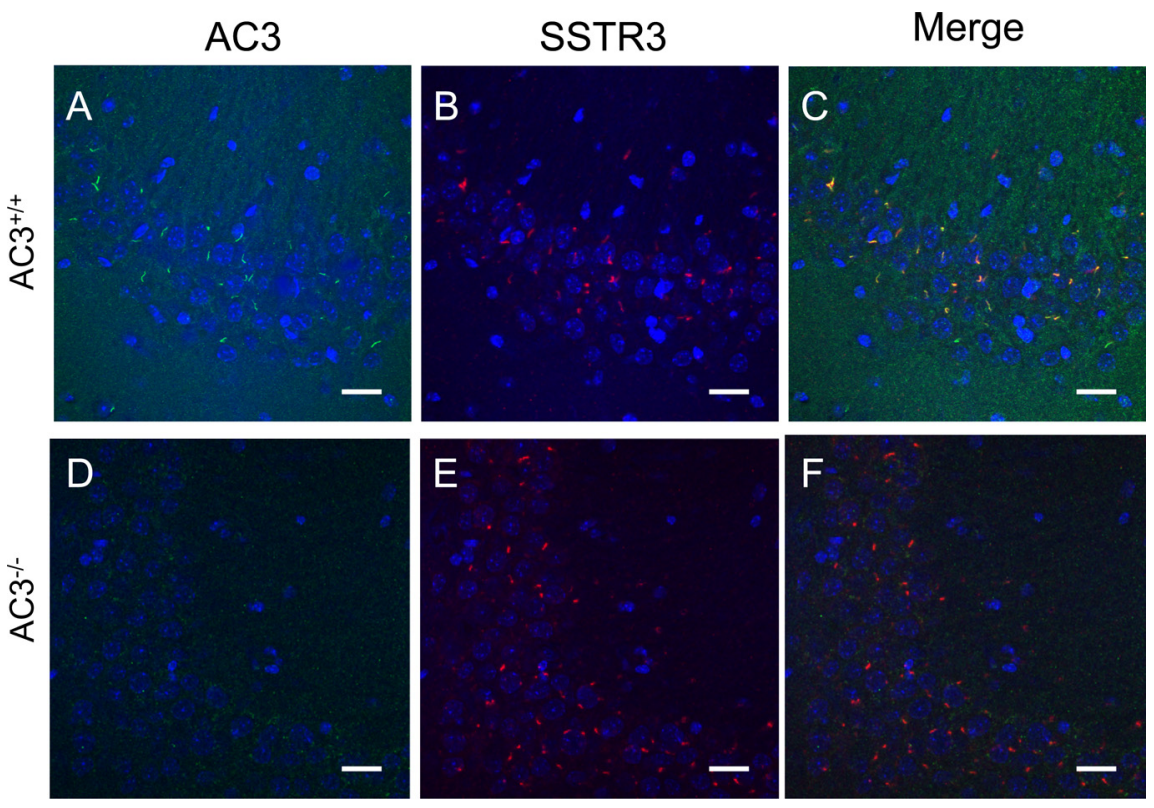

Hippocampal neurons in $A 3^{-1-}$ mice express primary cilia. $\boldsymbol{A}-\boldsymbol{C}$, Representative images of $A C 3$-immunoreactive colocalization of AC3 and SSTR3 (merge) (C). Scale bar, $20 \mu \mathrm{m}$. D-F, Representative images of immunoreactive cilia in the CA3 region of the hippocampus in $A C 3^{-1-}$ mice labeled with antibodies against $A C 3$ (green) (D), SSTR3 (red) (E), and colocalization of AC3 and SSTR3 (merge) $(\boldsymbol{F})$. Scale bar, $20 \mu \mathrm{m} . n=4$ for each genotype. Blue, Hoechst nuclear staining.

used in those studies using AC3 $3^{-1-}$ mice as a null control. We visualized the localization of AC3 in the hippocampus by immunohistochemical staining with an antibody against AC3. Our data indicate that $\mathrm{AC} 3$ in wild-type mice, but not $\mathrm{AC} 3^{-1-}$ mice, is present exclusively in primary cilia and is especially abundant in the pyramidal cell layer of the CA1 region (Fig. 1) and CA3 region (Fig. 2), as well as in the granular cell layer of the dentate gyrus region of the hippocampus (data not shown). These data establish the specificity of the AC3 antibody for AC3 and the presence of AC3 in primary cilia of hippocampal neurons. To determine whether AC3 is required for the formation or maintenance of primary cilia, hippocampal sections from $\mathrm{AC} 3^{+/+}$and $\mathrm{AC} 3^{-/-}$ mice were immunostained for another cilia marker, SSTR3. Immunostaining of hippocampal slices from $\mathrm{AC} 3^{+/+}$mice with 
A

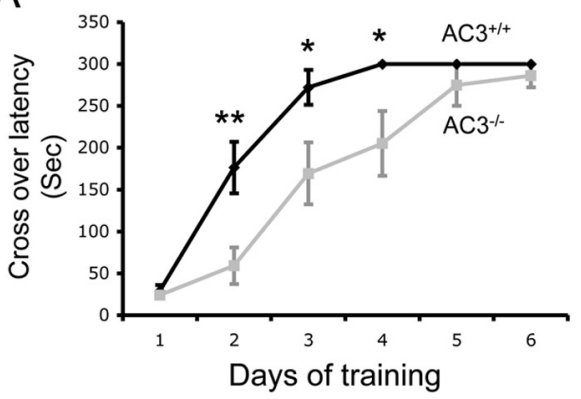

C

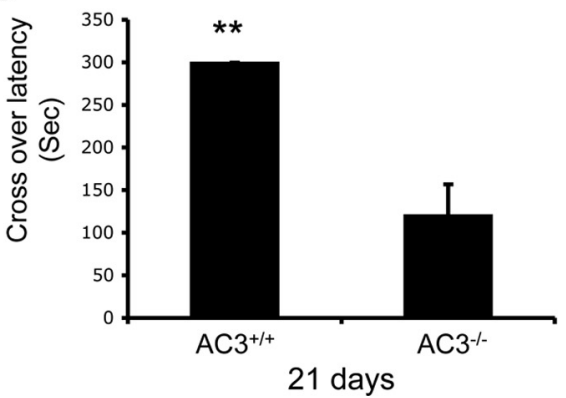

B

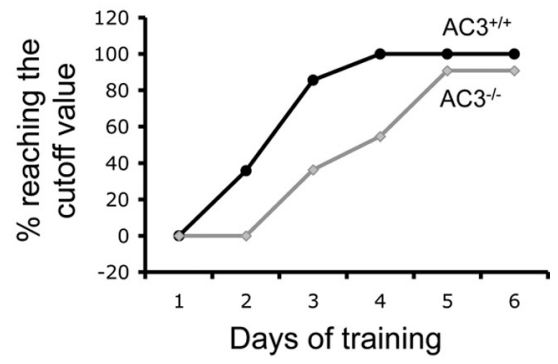

D

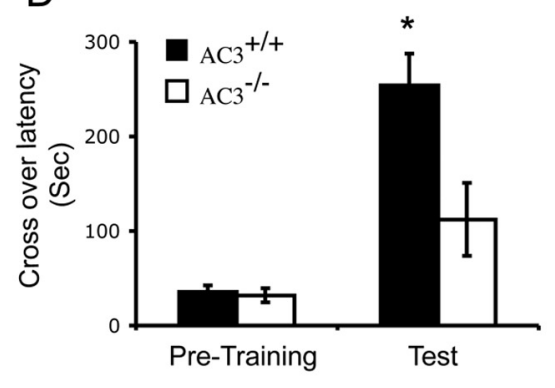

Figure 3. $\mathrm{AC} 3^{-1-}$ mice show impaired TDPA learning and memory. $A, A C 3^{-1-}$ mice $(n=11)$ learned TDPA slower than $\mathrm{AC} 3^{+/+}$mice $(n=14)$. The crossover latency for $\mathrm{AC} 3^{+/+}$and $\mathrm{AC} 3^{-/-}$mice during training for TDPA differed significantly on day $2(p=0.005)$, day $3(p=0.028)$, and day $4(p=0.034)$ of training. ${ }^{* *} p<0.01$; ${ }^{*} p<0.05$. Data are represented as means \pm SEM. $\boldsymbol{B}$, The percentage of AC3 ${ }^{-1-}$ mice $(n=11)$ reaching the cutoff value $(300 \mathrm{~s})$ for crossover latency during the course of TDPA training was lower than $\mathrm{AC} 3^{+/+}$mice $(n=14)$. $C$, Long-term memory for TDPA is impaired in $\mathrm{AC}^{-1-}$ mice. Long-term memory was tested $21 \mathrm{~d}$ after animals reached the cutoff value $(300 \mathrm{~s})$ for crossover latency during TDPA training. $\mathrm{AC} 3^{-1-}$ mice $(n=10)$ showed poorer retention of memory for TDPA training than $\mathrm{AC} 3^{+/+}$mice $(n=14)(p=0.001) .{ }^{* *} p<0.01$. Data are represented as means \pm SEM. $\boldsymbol{D}$, Short-term memory of $\mathrm{AC} 3^{-1-}$ mice for TDPA training is impaired. The crossover latency (in seconds) of animals entering the dark chamber was monitored $10 \mathrm{~min}$ after a single training session for TDPA. There were significant difference between $\mathrm{AC}^{+/+}$mice $(n=$ $8)$ and $\mathrm{AC} 3^{-1-}$ mice $(n=9)$ in crossover latency (in seconds) during the memory retention test $(p=0.014) .{ }^{*} p<0.05$. Data are represented as means \pm SEM.

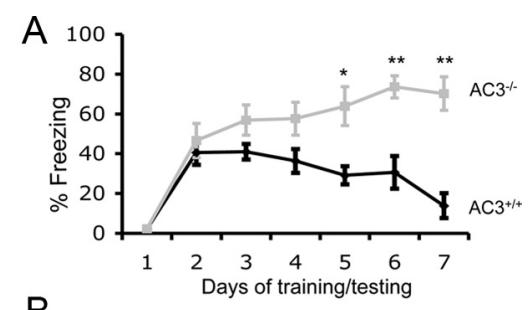

$\mathrm{B}$

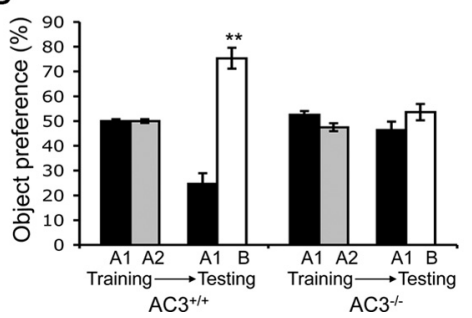

Figure 4. $\mathrm{AC}^{-1-}$ mice fail to exhibit short-term memory for novel objects or extinction of contextual memory. $A, A C 3^{+/+}$mice $(n=6)$ but not $\mathrm{AC}^{-1-}$ mice $(n=6)$ showed extinction of contextual memory during 7 d of extinction training [(day $5(p=0.015)$, day $6(p=0.023)$, and day $7(p=0.00004)] .^{* *} p<0.01 ;{ }^{*} p<0.05$. Data are represented as means \pm SEM. $B, A C{ }^{+/+}$mice $(n=8)$ but not $\mathrm{AC}^{-1-}$ mice $(n=7)$ showed short-term memory for a novel object. During training, both $\mathrm{AC}^{+/+}$mice $(n=8)$ and $\mathrm{AC}^{-1-}$ mice $(n=7)$ showed no preference for two identical objects ( $\mathrm{A} 1$ and $\mathrm{A} 2$ ). However, 5 min after training, $\mathrm{AC} 3^{+/+}$mice, but not $\mathrm{AC} 3^{-/-}$mice, showed a significant preference for the novel object $(\boldsymbol{B})\left(p=6.8 \times 10^{-7}\right) .{ }^{* *} p<0.01$. Data are represented as means \pm SEM. antibodies against SSTR3 and AC3 showed strong colocalization of SSTR3 and AC3 in primary cilia (Fig. 2C). The presence of primary cilia in $\mathrm{AC} 3^{-1-}$ mice indicates that $\mathrm{AC} 3$ is not required for the formation of primary cilia (Fig. 2E). Primary cilia stained with an antibody for SSTR3 appeared similar in $\mathrm{AC}^{+/+}$and $\mathrm{AC} 3^{-1-}$ mice (Fig. $2 B, E$ ). The presence of AC3 and SSTR3 in the same cilia of hippocampal neurons suggests that receptor-mediated regulation of $\mathrm{AC} 3$ may play a role in signaling mechanisms in primary cilia.

\section{TDPA memory is deficient in}

$\mathrm{AC}^{-1-}$ mice

We previously reported that $\mathrm{AC}^{-1-}$ mice show normal learning and memory for classic passive avoidance training (Wong et al., 2000). However, training for passive avoidance generates a very strong episodic memory, which is generated by shocking the mouse immediately after it crosses over into the dark compartment. During TDPA training, the crossover event and the shock are separated by $10 \mathrm{~min}$. Consequently, TDPA learning and memory requires multiple training sessions over a period of days and allows comparison of learning curves between wild-type and transgenic mouse strains. Accordingly, TDPA allows detection of learning and memory differences that otherwise would not be detected by passive avoidance training.

TDPA training revealed a number of significant differences between $\mathrm{AC} 3^{-/-}$mice and their $\mathrm{AC} 3^{+/+}$ littermates (Fig. 3). Although $\mathrm{AC}^{-1-}$ mice reached the same level of training as wild-type mice after $6 \mathrm{~d}$ of training, their initial rate of learning was significantly slower than $\mathrm{AC}^{+/+}$mice (Fig. $3 A$ ). For example, after one training session, the crossover latency for AC $3^{+/+}$mice was $176.4 \pm 30.9 \mathrm{~s}$, but only $59.1 \pm 21.8 \mathrm{~s}$ for $\mathrm{AC}^{-1-}$ mice (Fig. $3 A$ ). After two training sessions, $85.7 \%$ of $\mathrm{AC}^{+/+}$mice reached the cutoff time limit of $300 \mathrm{~s}$, but only $36.4 \%$ of $\mathrm{AC}^{-1-}$ mice (4 of 11 ) exhibited an escape latency of $300 \mathrm{~s}$ (Fig. $3 \mathrm{~B}$ ). All of the AC $3^{+/+}$mice but only $60 \%$ of the $\mathrm{AC}^{-1-}$ reached a crossover latency of $300 \mathrm{~s}$ after $4 \mathrm{~d}$ of training (Fig. $3 B$ ). We also tested the long-term memory of $\mathrm{AC}^{-1-}$ mice for TDPA learning $21 \mathrm{~d}$ after they reached a maximum crossover latency of $300 \mathrm{~s}$. Although AC3 ${ }^{+/+}$mice maintained their memory for TDPA training during this period, $\mathrm{AC}^{-1-}$ mice showed considerable memory loss after $21 \mathrm{~d}\left(\mathrm{AC}^{+/+}\right.$mice, $298.3 \pm 1.2 \mathrm{~s}$; $\mathrm{AC}^{-l-}$ mice, $119.3 \pm 37.7 \mathrm{~s}$ ) (Fig. $3 C$ ).

Since short-term and long-term memory are independently processed in the hippocampus and the underlying mechanisms involve separated signaling pathways (Satoh et al., 2007; Cowan, 2008), we also tested short-term memory of $\mathrm{AC}^{-1-}$ and $\mathrm{AC}^{+/+}$for TDPA after a single training session (Fig. 3D). There was a significant difference in crossover latency between $\mathrm{AC}^{+/+}$ and $\mathrm{AC} 3^{-1-}$ mice when they were tested $10 \mathrm{~min}$ after training $\left(253 \pm 33.6 \mathrm{~s}\right.$ for $\mathrm{AC}^{+/+}$mice, $112.2 \pm 38.6 \mathrm{~s}$ for $\mathrm{AC}^{-1-}$ mice; $p=0.014)$. A majority of the $\mathrm{AC}^{+/+}$mice $(62.5 \%)$ reached the $300 \mathrm{~s}$ cutoff latency (5 of 8 ). However, only $22.2 \%$ of AC3 ${ }^{-1-}$ 
mice exhibited an escape latency of $300 \mathrm{~s}$ ( 2 of 9). These data indicate that $\mathrm{AC} 3$ is critical for both short- and long-term TDPA memory.

\section{$\mathrm{AC}^{-/-}$mice do not exhibit extinction of contextual fear memory}

$\mathrm{AC}^{-1-}$ mice exhibited no impairment of memory for contextual fear conditioning, another form of hippocampus-dependent memory (Fig. $4 A$ ). AC3 ${ }^{+/+}$mice and $\mathrm{AC}^{-1-}$ mice showed indistinguishable freezing behavior when returned to the training context $24 \mathrm{~h}$ after training for context $\left(40.6 \pm 6.2 \%\right.$ for $\mathrm{AC} 3^{+/+}$ mice and $46.7 \pm 8.6 \%$ for $\mathrm{AC} 3^{-1-}$ mice; $p=0.6$ ). However, $\mathrm{AC}^{+/+}$mice, but not $\mathrm{AC} 3^{-1-}$, exhibited memory extinction for contextual fear conditioning when they were brought back into the training box without shock on consecutive days (Fig. 4A). Indeed, it appears that the AC3 ${ }^{-1-}$ mice continued to consolidate contextual memory during testing for extinction with the freezing time increasing from $45 \%$ to $70 \%$ over the course of extinction training. Apparently, $\mathrm{AC} 3^{-/-}$mice were unable to learn that the context is no longer associated with a shock during extinction training. This suggests that CAMP production by AC3 in the cilia of neurons is necessary for extinction of contextual memory, which is another form of learning.

\section{$\mathrm{AC}^{-/-}$mice fail to exhibit short-term memory for novel object recognition}

When exposed to a familiar object alongside a novel object, rodents prefer to explore the new object, indicating that the animals have a memory for the familiar object. We examined novel object recognition because AC3 and SSTR3 colocalize to the same cilia in hippocampal neurons (Fig. 2C) and SSTR3 is critical for object recognition memory (Einstein et al., 2010). During the initial training, $\mathrm{AC} 3^{+/+}$and $\mathrm{AC} 3^{-/-}$mice spent the same amount of time examining the two identical objects, A1 and A2. When tested 5 min later with the replacement of object A2 with a new object B, $\mathrm{AC} 3^{+/+}$mice showed a strong preference for the new object $\mathrm{B}$ while $\mathrm{AC} 3^{-1-}$ mice showed no preference for the new object (Fig. $4 B$ ). Similar behaviors were observed when tested with another cohort of $\mathrm{AC}^{-1-}$ mice tested $20 \mathrm{~min}$ after training (data not shown). This indicates that $\mathrm{AC}^{-1-}$ mice fail to distinguish novel from familiar objects or that they have no short-term memory for novel object recognition.

\section{Discussion}

Studies using transgenic animals have established that the cAMP signaling is essential for learning and memory (Wu et al., 1995; Abel et al., 1997; Wong et al., 1999; Pineda et al., 2004). To date, clones for 10 adenylyl cyclases have been isolated, each with unique regulatory properties. Although almost every isoform of adenylyl cyclase is expressed in the hippocampus (Visel et al., 2006), only the calmodulin-stimulated adenylyl cyclases have been shown to be critical for hippocampus-dependent long-term memory (Wu et al., 1995; Wong et al., 1999). With the exception of AC5, which is critical for striatum-dependent learning (Kheirbek et al., 2008; Kheirbek et al., 2009), the contribution of other adenylyl cyclases to learning and memory is largely unknown. Moreover, the importance of adenylyl cyclase activity in neuronal cilia for learning and memory or memory extinction has not been addressed. Since AC3 is expressed exclusively in primary cilia throughout the brain (Bishop et al., 2007), it was important to investigate the contribution of AC3 to various types of leaning and memory.
In this study, we discovered that $\mathrm{AC} 3^{-1-}$ mice exhibit defects in several forms of learning and memory. Although AC3 ${ }^{-1-}$ mice exhibit normal learning and memory for passive avoidance as well as contextual fear conditioning, their learning curve for TDPA is significantly slower than wild-type mice. Furthermore, both short-term and long-term memory for TDPA are impaired in $\mathrm{AC}^{-1-}$ mice. Moreover, $\mathrm{AC} 3^{-1-}$ mice also failed to exhibit short-term memory for novel objects or extinction of contextual memory. Apparently, AC3 ${ }^{-1-}$ mice are able to recognize contexts since they exhibit classical contextual and passive avoidance memory. It appears that the more challenging memory tasks depend on AC3 activity. Since extinction of contextual memory and TDPA learning requires multiple training sessions, these data indicate that $\mathrm{AC} 3$ is required for more difficult forms of memory requiring repeated training sessions. Nevertheless, the fact that long-term memory for TDPA is poorer in $\mathrm{AC} 3^{-1-}$ mice is consistent with the possibility that cAMP signals generated in primary cilia by AC3 may support translational or transcriptional events required for formation or maintenance of long-term memory. Acquisition and extinction of contextual memory both depend on CAMP signaling. However, the data in this paper indicate that CAMP generated in primary cilia is critical for extinction of contextual memory but not crucial for acquisition of contextual memory. Collectively, these observations emphasize the importance of different intracellular cAMP pools for specific learning and memory tasks.

It is interesting that $\mathrm{AC} 3^{-1-}$ mice and SSTR $3^{-1-}$ mice both are deficient on novel object memory, suggesting that cAMP signals in primary cilia are critical for novel object memory. However, in contrast to $\mathrm{AC} 3^{-1-}$ mice, SSTR3 ${ }^{-1-}$ mice showed no decrease in object recognition memory $5 \mathrm{~min}$ after training but did so $60 \mathrm{~min}$ after training (Einstein et al., 2010). This difference between the two transgenic strains may reflect the fact that there are multiple G-protein receptors in the primary cilia of CNS neurons that can couple to AC3. For example, the 5-hydroxytryptamine-6 receptor (5-HT6) couples to adenylyl cyclase (Sebben et al., 1994; Unsworth and Molinoff, 1994) and is expressed in primary cilia of CNS neurons (Brailov et al., 2000). In addition, MCHR1 is also located in primary cilia of CNS neurons (Berbari et al., 2008). Both of these G-protein receptors are implicated in learning and memory.

In summary, $\mathrm{AC}^{-1-}$ mice show impaired learning and memory for TDPA training, and no short-term memory for novel objects or extinction of contextual memory. Since neuronal AC3 is expressed exclusively in primary cilia, these data indicate that cAMP signals generated in the primary cilia by AC3 are crucial for some forms of learning and memory.

\section{References}

Abel T, Nguyen PV, Barad M, Deuel TA, Kandel ER, Bourtchouladze R (1997) Genetic demonstration of a role for PKA in the late phase of LTP and in hippocampus-based long-term memory. Cell 88:615-626.

Adamantidis A, Thomas E, Foidart A, Tyhon A, Coumans B, Minet A, Tirelli E, Seutin V, Grisar T, Lakaye B (2005) Disrupting the melaninconcentrating hormone receptor 1 in mice leads to cognitive deficits and alterations of NMDA receptor function. Eur J Neurosci 21:2837-2844.

Berbari NF, Bishop GA, Askwith CC, Lewis JS, Mykytyn K (2007) Hippocampal neurons possess primary cilia in culture. J Neurosci Res 85:1095-1100.

Berbari NF, Lewis JS, Bishop GA, Askwith CC, Mykytyn K (2008) BardetBiedl syndrome proteins are required for the localization of $\mathrm{G}$ protein-coupled receptors to primary cilia. Proc Natl Acad Sci U S A 105:4242-4246.

Bishop GA, Berbari NF, Lewis J, Mykytyn K (2007) Type III adenylyl cyclase localizes to primary cilia throughout the adult mouse brain. J Comp Neurol 505:562-571.

Brailov I, Bancila M, Brisorgueil MJ, Miquel MC, Hamon M, Vergé D (2000) 
Localization of 5-HT(6) receptors at the plasma membrane of neuronal cilia in the rat brain. Brain Res 872:271-275.

Cowan N (2008) What are the differences between long-term, short-term, and working memory? Prog Brain Res 169:323-338.

Einstein EB, Patterson CA, Hon BJ, Regan KA, Reddi J, Melnikoff DE, Mateer MJ, Schulz S, Johnson BN, Tallent MK (2010) Somatostatin signaling in neuronal cilia is critical for object recognition memory. J Neurosci 30:4306-4314.

Händel M, Schulz S, Stanarius A, Schreff M, Erdtmann-Vourliotis M, Schmidt H, Wolf G, Höllt V (1999) Selective targeting of somatostatin receptor 3 to neuronal cilia. Neuroscience 89:909-926.

Johnson JL, Leroux MR (2010) cAMP and cGMP signaling: sensory systems with prokaryotic roots adopted by eukaryotic cilia. Trends Cell Biol 20:435-444.

Kheirbek MA, Beeler JA, Ishikawa Y, Zhuang X (2008) A cAMP pathway underlying reward prediction in associative learning. J Neurosci 28:11401-11408.

Kheirbek MA, Britt JP, Beeler JA, Ishikawa Y, McGehee DS, Zhuang X (2009) Adenylyl cyclase type 5 contributes to corticostriatal plasticity and striatum-dependent learning. J Neurosci 29:12115-12124.

Kwon RY, Temiyasathit S, Tummala P, Quah CC, Jacobs CR (2010) Primary cilium-dependent mechanosensing is mediated by adenylyl cyclase 6 and cyclic AMP in bone cells. FASEB J 24:2859-2868.

Lee JH, Gleeson JG (2010) The role of primary cilia in neuronal function. Neurobiol Dis 38:167-172.

Masyuk AI, Gradilone SA, Banales JM, Huang BQ, Masyuk TV, Lee SO, Splinter PL, Stroope AJ, Larusso NF (2008) Cholangiocyte primary cilia are chemosensory organelles that detect biliary nucleotides via P2Y12 purinergic receptors. Am J Physiol Gastrointest Liver Physiol 295: G725-G734.

Pineda VV, Athos JI, Wang H, Celver J, Ippolito D, Boulay G, Birnbaumer L, Storm DR (2004) Removal of G(ialpha1) constraints on adenylyl cyclase in the hippocampus enhances LTP and impairs memory formation. Neuron 41:153-163.

Praetorius HA, Spring KR (2005) A physiological view of the primary cilium. Annu Rev Physiol 67:515-529.

Raychowdhury MK, Ramos AJ, Zhang P, McLaughin M, Dai XQ, Chen XZ, Montalbetti N, Del Rocío Cantero M, Ausiello DA, Cantiello HF (2009) Vasopressin receptor-mediated functional signaling pathway in primary cilia of renal epithelial cells. Am J Physiol Renal Physiol 296:F87-F97.

Satir P, Pedersen LB, Christensen ST (2010) The primary cilium at a glance. J Cell Sci 123:499-503.

Satoh Y, Endo S, Ikeda T, Yamada K, Ito M, Kuroki M, Hiramoto T, Imamura O, Kobayashi Y, Watanabe Y, Itohara S, Takishima K (2007) Extracellular signal-regulated kinase 2 (ERK2) knockdown mice show deficits in long-term memory; ERK2 has a specific function in learning and memory. J Neurosci 27:10765-10776.
Schulz S, Händel M, Schreff M, Schmidt H, Höllt V (2000) Localization of five somatostatin receptors in the rat central nervous system using subtype-specific antibodies. J Physiol Paris 94:259-264.

Sebben M, Ansanay H, Bockaert J, Dumuis A (1994) 5-HT6 receptors positively coupled to adenylyl cyclase in striatal neurones in culture. Neuroreport 5:2553-2557.

Shimizu K, Phan T, Mansuy IM, Storm DR (2007) Proteolytic degradation of SCOP in the hippocampus contributes to activation of MAP kinase and memory. Cell 128:1219-1229.

Singla V, Reiter JF (2006) The primary cilium as the cell's antenna: signaling at a sensory organelle. Science 313:629-633.

Snell WJ, Pan J, Wang Q (2004) Cilia and flagella revealed: from flagellar assembly in Chlamydomonas to human obesity disorders. Cell 117: 693-697.

Unsworth CD, Molinoff PB (1994) Characterization of a 5-hydroxytryptamine receptor in mouse neuroblastoma N18TG2 cells. J Pharmacol Exp Ther 269:246-255.

Visel A, Alvarez-Bolado G, Thaller C, Eichele G (2006) Comprehensive analysis of the expression patterns of the adenylate cyclase gene family in the developing and adult mouse brain. J Comp Neurol 496:684-697.

Wang B, Hu Q, Hearn MG, Shimizu K, Ware CB, Liggitt DH, Jin LW, Cool BH, Storm DR, Martin GM (2004a) Isoform-specific knockout of FE65 leads to impaired learning and memory. J Neurosci Res 75:12-24.

Wang H, Ferguson GD, Pineda VV, Cundiff PE, Storm DR (2004b) Overexpression of type-1 adenylyl cyclase in mouse forebrain enhances recognition memory and LTP. Nat Neurosci 7:635-642.

Wang Y, Zhang M, Moon C, Hu Q, Wang B, Martin G, Sun Z, Wang H (2009a) The APP-interacting protein FE65 is required for hippocampusdependent learning and long-term potentiation. Learn Mem 16:537-544.

Wang Z, Li V, Chan GC, Phan T, Nudelman AS, Xia Z, Storm DR (2009b) Adult type 3 adenylyl cyclase-deficient mice are obese. PLoS One 4:e6979.

Wong ST, Athos J, Figueroa XA, Pineda VV, Schaefer ML, Chavkin CC, Muglia LJ, Storm DR (1999) Calcium-stimulated adenylyl cyclase activity is critical for hippocampus-dependent long-term memory and late phase LTP. Neuron 23:787-798.

Wong ST, Trinh K, Hacker B, Chan GC, Lowe G, Gaggar A, Xia Z, Gold GH, Storm DR (2000) Disruption of the type III adenylyl cyclase gene leads to peripheral and behavioral anosmia in transgenic mice. Neuron 27:487-497.

Wu ZL, Thomas SA, Villacres EC, Xia Z, Simmons ML, Chavkin C, Palmiter RD, Storm DR (1995) Altered behavior and long-term potentiation in type I adenylyl cyclase mutant mice. Proc Natl Acad Sci U S A 92:220-224.

Zhang M, Moon C, Chan GC, Yang L, Zheng F, Conti AC, Muglia L, Muglia LJ, Storm DR, Wang H (2008) Ca-stimulated type 8 adenylyl cyclase is required for rapid acquisition of novel spatial information and for working/episodic-like memory. J Neurosci 28:4736-4744. 